(2) Open Access Full Text Article

\title{
Hippuric acid nanocomposite enhances doxorubicin and oxaliplatin-induced cytotoxicity in MDA-MB23 I, MCF-7 and Caco2 cell lines
}

This article was published in the following Dove Press journal:

Drug Design, Development and Therapy

II January 2013

Number of times this article has been viewed

\author{
Samer Hasan Hussein Al Ali ${ }^{1}$ \\ Mothanna Al-Qubaisi ${ }^{2}$ \\ Mohd Zobir Hussein ${ }^{1,3}$ \\ Maznah Ismail2,4 \\ Saifullah Bullo' \\ 'Department of Chemistry, Faculty \\ of Science, Universiti Putra \\ Malaysia, Serdang, Selangor, Malaysia; \\ ${ }^{2}$ Laboratory of Molecular Biomedicine, \\ Institute of Bioscience, Universiti \\ Putra Malaysia, Serdang, Selangor, \\ Malaysia; ${ }^{3}$ Advanced Materials and \\ Nanotechnology Laboratory, Institute \\ of Advanced Technology, Universiti \\ Putra Malaysia, Serdang, Selangor, \\ Malaysia; ${ }^{4}$ Department of Nutrition \\ and Dietetics, Faculty of Medicine \\ and Health Science, Universiti Putra \\ Malaysia, Serdang, Selangor, Malaysia
}

Correspondence: Mohd Zobir Hussein Department of Chemistry, Faculty of Science, Universiti Putra Malaysia, Serdang, Selangor, Malaysia

$\mathrm{Tel}+6038946680 \mathrm{I}$

Fax +60 389435380

Email mzobir@science.upm.edu.my
Background: The aim of the current study is to design a new nanocomposite for inducing cytotoxicity of doxorubicin and oxaliplatin toward MDA-MB231, MCF-7, and Caco2 cell lines. A hippuric acid (HA) zinc layered hydroxide (ZLH) nanocomposite was synthesized under an aqueous environment using $\mathrm{HA}$ and zinc oxide $(\mathrm{ZnO})$ as the precursors.

Methods: The hippuric acid nanocomposite (HAN) was prepared by the direct reaction of a HA solution with an aqueous suspension of $\mathrm{ZnO}$.

Results: The basal spacing of the nanocomposite was $21.3 \AA$, which is average of four harmonics at $2 \theta=8.32^{\circ}, 12.50^{\circ}, 16.68^{\circ}$, and $20.84^{\circ}$. This result indicates that the hippurate anion was successfully intercalated into the interlayer space of ZLH. The combinations of HAN with chemotherapy (drugs) has inhibited the cell growth of the MDA-MB231, MCF-7, and Caco2

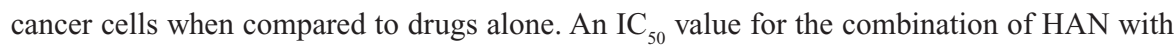
doxorubicin toward MCF-7 is $0.19 \pm 0.15 \mu \mathrm{g} / \mathrm{mL}$ and toward MDA-MB231 is $0.13 \pm 0.10$ $\mu \mathrm{g} / \mathrm{mL}$. Similarly, the $\mathrm{IC}_{50}$ for the combination of HAN with oxaliplatin toward Caco 2 is $0.24 \pm 0.11 \mu \mathrm{g} / \mathrm{mL}$. In the antiproliferative results, the equal combination of $\mathrm{HAN}(0.5 \mu \mathrm{g} / \mathrm{mL})$ with doxorubicin $(0.5 \mu \mathrm{g} / \mathrm{mL})$ has reduced the cell proliferation in MCF-7 and MDA-MB231 cells into $37.3 \%$ and $17.6 \%$, respectively after 24 hours. Similarly, the antiproliferation percentage for equal combination HAN with oxaliplatin $(5.00 \mu \mathrm{g} / \mathrm{mL})$ toward Caco 2 is $72.7 \%$ after 24 hours.

Conclusion: The resulting combination HAN with drugs has exhibited higher inhibition in cells growth in all cancer cell lines.

Keywords: hippuric acid nanocomposite, zinc-layered hydroxide, doxorubicin, oxaliplatin, MDA-MB231, MCF-7, Caco2 cell lines

\section{Introduction}

The structure of layered double hydroxides (LDHs) and zinc layered hydroxide (ZLH) are derived from the structure of brucite, $\mathrm{Mg}(\mathrm{OH})_{2}$. Brucite is the natural mineral form of magnesium hydroxide. The magnesium ions with a (2+) charge are centered to six octahedrally hydroxides with a (1-) charge. Each hydroxide is bonded to three magnesium atoms, resulting in neutral layers that interact with each other through weak hydrogen bonds. ${ }^{1}$ The chemical structure of LDHs can be represented by the general formula: ${ }^{2}$

$$
\left[\mathrm{M}_{1-\mathrm{x}}^{2+} \mathrm{M}_{\mathrm{x}}^{3+}(\mathrm{OH})_{2}\right]^{\mathrm{x}+}\left(\mathrm{A}^{\mathrm{n}-}\right)_{\mathrm{x} / \mathrm{n}} \cdot \mathrm{mH}_{2} \mathrm{O}
$$

and the layered hydroxide salts can be represented as follows:

$$
\left[\mathrm{M}^{2+}(\mathrm{OH})_{2-\mathrm{x}}\left(\mathrm{A}^{n-}\right)_{x / n} \cdot \mathrm{mH}_{2} \mathrm{O}\right]
$$


where $\mathrm{M}^{2+}$ is a divalent cation, $\mathrm{M}^{3+}$ is a trivalent cation, and $\mathrm{A}^{\mathrm{n}-}$ is an exchangeable anion with a charge $\left(\mathrm{n}^{-}\right){ }^{3}$

The flexibility in composition of LDH and ZLH, and easily replaced the anions located in the interlayer regions leaded to an increased level of interest in these materials. As a result of the relative ease to synthesize, LDHs and LHSs represent inexpensive and versatile compounds that can be used in different advanced applications, such as in a controlled release system for drugs. ${ }^{4}$

When applying two drugs in a system, the interaction may yield an additive effect, where the total response is the sum of the two drugs individually. In addition, the combination of these two drugs may result in a greater response, which is called a synergistic response. On the other hand, the interaction between the two drugs may also lead to a smaller response, whereby one drug blocks the effects of the other. It is important to note that the synergistic effect of the combination of two drugs against one target has recently been of particular interest.,

Hippuric acid (benzoylaminoethanoic acid) can be obtained from the urine of horses and other herbivores. A biological investigation of hippuric acid shows that it has limited antimicrobial activity at acidic $\mathrm{pH}$ values, ${ }^{7}$ and has synergistic potentiating effects on the selective toxicity of a mixture of 13 substances within the circulatory system. ${ }^{8}$ From our previous work, hippurate nanocompsite HAN has shown synergistic activity with tamoxifen against the HepG2 cell line. ${ }^{9}$ Therefore the aim of this present work is to study the synergistic properties of HAN when combined with doxorubicin and oxaliplatin against different cell lines (MDA-MB231, MCF-7, and Caco2). It should be known that oxaliplatin has been commonly used for chemotherapy in colon cancer, ${ }^{10}$ while doxorubicin is the most common treatment for breast cancer. ${ }^{11,12}$

\section{Materials and methods Materials}

Hippuric acid (98\% purity) was purchased from Merck (Darmstadt, Germany) and was used as received. Doxorubicin (98\% purity) and oxaliplatin was purchased from SigmaAldrich (St Louis, MO). Zinc oxide ( $\mathrm{ZnO}$ ) of American Chemical Society reagent grade was purchased from Fisher Scientific (Waltham, MA), and dimethyl sulfoxide (DMSO) was purchased from Ajax Finechem (Thermo Fisher Scientific, Waltham, MA) and used without further purification. The cell lines MCF-7, MDA-MB231, and Caco2 were purchased from the American Type Culture Collection. Deionized water was used in all the experiments.

\section{Preparation of hippuric acid nanocomposite, HAN}

The hippuric acid nanocomposite (HAN) was synthesized by the direct method using $\mathrm{ZnO}$ as the starting material as reported previously, ${ }^{9,13,14}$ with minor modifications. The hippuric acid solution (0.01 Mole) was prepared using $1.8 \mathrm{~g}$ of hippuric acid in $20 \mathrm{~mL}$ of DMSO, and was adjusted to $50 \mathrm{~mL}$ by the addition of deionized water. The $\mathrm{ZnO}$ powder $(0.2 \mathrm{~g})$ was suspended in $50 \mathrm{~mL}$ of water. Hippurate solution was added slowly dropwise to the suspended $\mathrm{ZnO}$, with vigorous stirring until the addition was complete and the solution became clear. The $\mathrm{pH}$ was adjusted to 7.9 using an aqueous solution of $\mathrm{NaOH}(0.5 \mathrm{Mol} / \mathrm{L})$ to get the white precipitate; the resulting precipitate was magnetically stirred for 18 hours at $70^{\circ} \mathrm{C}$. The resulting product was centrifuged, thoroughly washed with deionized water, dried in an oven at $60^{\circ} \mathrm{C}$ overnight, and kept in a sample bottle for further use.

\section{MTT cytotoxicity assay}

Breast cancer cell lines (MCF-7 and MDA-MB231) and heterogeneous human epithelial colorectal adenocarcinoma cells (Caco2) were seeded into 96-well plates and kept at $5 \% \mathrm{CO}_{2}$ at $37^{\circ} \mathrm{C}$ for 24 hours, at a cell density of $40-50 \%$ confluence. The cells were then treated with doxorubicin and oxaliplatin alone, and with an equivalent cytostatic mixture of either hippuric acid or HAN. After 72 hours of incubation, $20 \mu \mathrm{L}$ of tetrazolium salts (3-(4,5-Dimethylthiazol-2-yl)-2,5diphenyltetrazolium bromide) MTT solution $(5 \mathrm{mg} / \mathrm{mL})$ was added to each well and incubated for 4 hours. The microplates were turned swiftly to discard the medium, and the formazan precipitate was dissolved in $10 \%$ sodium dodecyl sulfate in DMSO containing $0.6 \%$ acetic acid. The microplates were then gently shaken in the dark for 30 minutes, and absorbance at $570 \mathrm{~nm}$ and $630 \mathrm{~nm}$ (background) was measured with a microtiter plate reader. All experiments were carried out in triplicate. The $\mathrm{IC}_{50}$ was generated from the dose-response curves for the cell line.

\section{Antiproliferation assay}

MCF-7, MDA-MB231, and Caco2 cells were first seeded in six-well plates. After incubation for 24 hours for cell attachment, exponentially growing cells were exposed to doxorubicin $(0.5 \mu \mathrm{g} / \mathrm{mL})$ alone, or to oxaliplatin $(5 \mu \mathrm{g} / \mathrm{mL})$ and its combination with hippuric acid or HAN. The plates were incubated at $37^{\circ} \mathrm{C}$ at $5 \% \mathrm{CO}_{2}$ for 24,48 , and 72 hours. After incubation, the media was aspirated off, washed with cold phosphate buffered saline to get rid of the dead cells, and replaced with $1 \mathrm{~mL}$ of $0.05 \%(2 \mathrm{mg} / \mathrm{mL})$ trypsin-EDTA. 
The plates were incubated at $37^{\circ} \mathrm{C}$ for $10-15$ minutes, until the majority of the cells had lifted off. The cells were then harvested. The cell suspension was centrifuged at 1000 rpm for 10 minutes, and the supernatant was discarded. Twenty $\mu \mathrm{L}$ of cell suspension was mixed with $20 \mu \mathrm{L}$ of $0.4 \%$ trypan blue solution. Cells were resuspended and dyeexcluding viable cells were microscopically counted using a hemocytometer.

\section{Statistical analysis}

All data were expressed as the means \pm standard deviation of the values obtained from three replicates. Using analysis of variance, statistical significance was determined. Mean values with probability values of $P<0.05$ were taken as statistically significant.

\section{Characterization}

Powder X-ray diffraction patterns were recorded with a Shimadzu XRD-6000 instrument (Shimazdu Corporation, Tokyo, Japan) using $\mathrm{CuK}_{\alpha}$ radiation $(\lambda=1.5418 \AA$ ) and a dwell time of 4 degrees per minute. Cell count was carried out with a Neubauer hemocytometer (Weber Scientific International Ltd, Middlesex, UK) by way of clear field microscopy (Nikon Corporation, Tokyo, Japan).

\section{Results and discussion Powder X-ray diffraction}

Figure 1 shows the powder X-ray diffraction patterns for hippuric acid, $\mathrm{ZnO}$, and $\mathrm{HAN}$, respectively, which was reported previously in our work. ${ }^{9}$ The mechanism of formation of hippurate nanocomposite synthesized by direct reaction of $\mathrm{ZnO}$ in an aqueous environment can be described as follows. ${ }^{15}$ Hydrolyzed $\mathrm{ZnO}$ in an aqueous environment leads to the formation of thin layers of zinc hydroxide $\left(\mathrm{Zn}(\mathrm{OH})_{2}\right)$ on the surface of the solid particles. $\mathrm{Zn}^{2+}$ species form of dissociation of $\mathrm{Zn}(\mathrm{OH})_{2}$ in a solution-solid interface. In addition, $\mathrm{Zn}^{2+}$ ions react with hydroxyls, hippurate anions, and water in the solution to form the layered HAN nanocomposite. Figure 1A shows that $\mathrm{ZnO}$ exhibited three intense peaks between $30^{\circ}$ and $40^{\circ}$, corresponding to diffractions due to the 100,002 , and 101 planes. Complete disappearance of the intense peaks of the $\mathrm{ZnO}$ phase and the appearance of a new intense peak at low $2 \theta$ with a d value of $21.3 \AA$ indicated that the sample of HAN is pure phase, and that the $\mathrm{ZnO}$ was completely converted to ZLH. In addition, Figure $1 \mathrm{~B}$ shows another four harmonics at $2 \theta=8.32^{\circ}, 12.50^{\circ}, 16.68^{\circ}$, and $20.84^{\circ}$, with $\mathrm{d}$ values of $10.70 \AA, 7.10 \AA, 5.30 \AA$, and $4.30 \AA$, respectively, resulting in an average d value of $21.30 \AA .{ }^{9}$

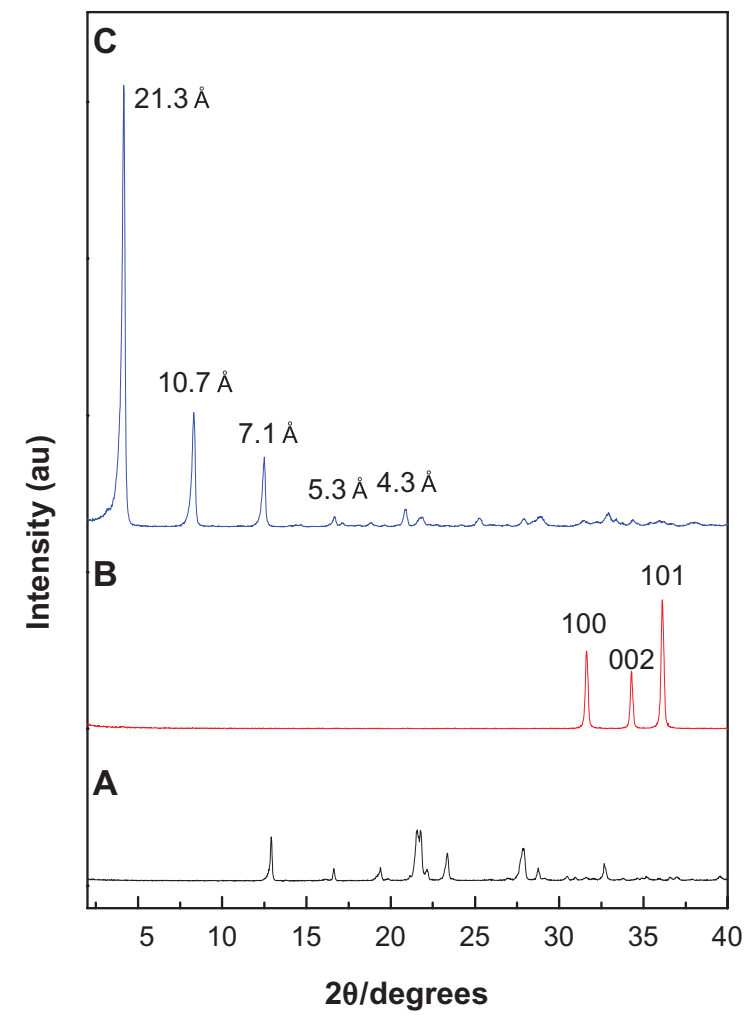

Figure I Powder X-ray diffraction patterns of (A) hippuric acid, (B) $\mathrm{ZnO}$, and (C) HAN.

Abbreviations: $\mathrm{ZnO}$, zinc oxide; $\mathrm{HAN}$, hippuric acid nanocomposite.

\section{Cytotoxicity of the combination of HAN with doxorubicin and oxaliplatin}

In this work we used breast cancer cells MCF-7 and MDAMB231 because they retained several ideal characteristics particular to the mammary epithelium. ${ }^{16,17} \mathrm{Caco} 2$ was used as an in vitro model for colon cancer, which is the second most common cause of cancer in women, and the third most common in men. ${ }^{18}$ We found that HAN could potentiate the killing of breast and colon cancer cells induced by chemotherapeutic agents. In the absence of hippuric acid or $\mathrm{HAN}$, the doxorubicin suppresses the cells growth of MCF-7 and MDA-MB231 cell lines with $\mathrm{IC}_{50}$ values $0.29 \pm 0.09 \mu \mathrm{g} / \mathrm{mL}$ and $0.20 \pm 0.06 \mu \mathrm{g} / \mathrm{mL}$, respectively. In Figure 2 and Table 1 , the combination of hippuric acid with doxorubicin dose not shown significant reduction in the cell viability $(P>0.05)$. When closely examining each part in Figure 2, it is apparent that the combination of doxorubicin with HAN has a higher tumor inhibition efficiency compared to doxorubicin alone, and the $\mathrm{IC}_{50}$ values were $0.19 \mu \mathrm{g} / \mathrm{mL} \pm 0.15 \mu \mathrm{g} / \mathrm{mL}$ and $0.13 \mu \mathrm{g} / \mathrm{mL} \pm 0.10$ for the MCF-7 and MDA-MB231 cell lines, respectively. There was a significant decrease of MDAMB231 and $\mathrm{Caco} 2$ viability at the combination concentration as low as $0.31 \mu \mathrm{g} / \mathrm{mL}$ till $20 \mu \mathrm{g} / \mathrm{mL}(P<0.05, P=0.01$, 

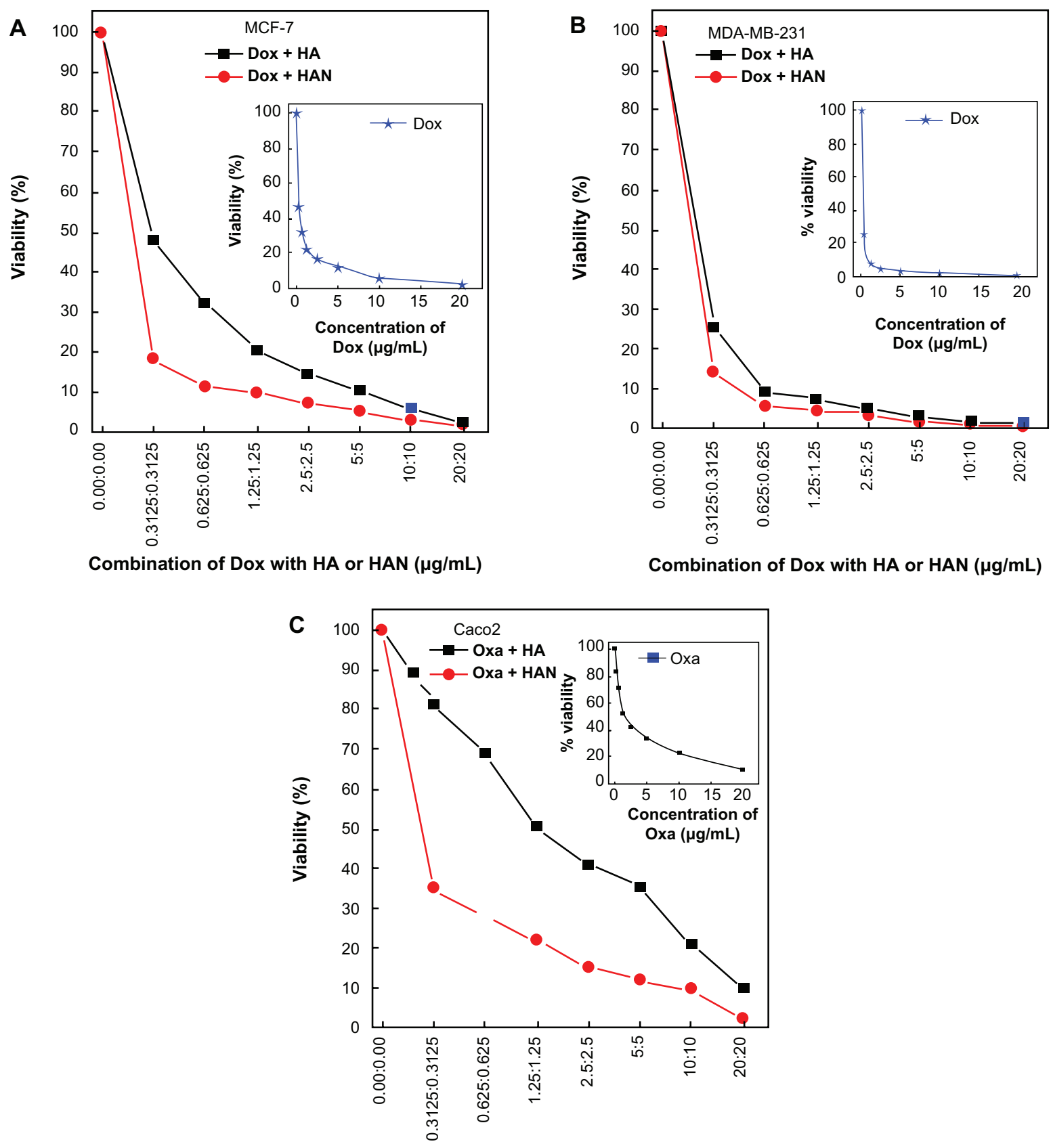

Combination of Oxa with HA or HAN $(\mu \mathrm{g} / \mathrm{mL})$

Figure 2 MTT assays of (A) MCF-7, (B) MDA-MB23I, and (C) Caco2 cell lines after 72 hours of treatment.

Abbreviations: Dox, doxorubicin; HA, hippuric acid; HAN, hippuric acid nanocomposite; Oxa, oxaliplatin.

respectively). This result indicates that the suppression percentage in cells MCF-7 and MDA-MB231 are $34.4 \%$ and $35.0 \%$, respectively.

Similarly, the combination of oxaliplatin with HAN against the Caco 2 cells shows an suppression efficiency with $\mathrm{IC}_{50}$ of $0.24 \mu \mathrm{g} / \mathrm{mL} \pm 0.11$ compared with $1.48 \mu \mathrm{g} / \mathrm{mL} \pm 0.10$ for oxaliplatin alone. Our findings demonstrated that the co-treatment of Caco 2 cell by oxaliplatin and HAN mixture shows maximal efficacy, this may be due to effect of the ZLH nanolayer, which facilitates the entry of the oxaliplatin drug, as compared to doxorubicine.

\section{Antiproliferative effect of free doxorubicin or oxaliplatin and a combination of drugs with hippuric acid and HAN}

Figure 3 shows the effect of free doxorubicin and oxaliplatin drugs, and the combination of hippuric acid or HAN with that drugs on the proliferation of MCF-7, MDA-MB231, 
Table I IC I $_{50}$ value of different cell lines treated with free doxorubicin or oxaliplatin, and a combination of free drugs with hippuric acid and HAN

\begin{tabular}{|c|c|c|c|c|c|c|c|c|c|}
\hline & \multicolumn{3}{|c|}{ MCF-7 } & \multicolumn{3}{|c|}{ MDA-MB23 I } & \multicolumn{3}{|c|}{ Caco2 } \\
\hline & Dox & Dox + HA & Dox + HAN & Dox & Dox + HA & Dox + HAN & Oxa & Oxa + HA & Oxa + HAN \\
\hline $\mathrm{IC}_{50}$ & $0.29 \pm 0.09$ & $0.30 \pm 0.06$ & $0.19 \pm 0.15$ & $0.20 \pm 0.06$ & $0.21 \pm 0.07$ & $0.13 \pm 0.10$ & $1.48 \pm 0.10$ & $1.29 \pm 0.03$ & $0.24 \pm 0.11$ \\
\hline
\end{tabular}

Abbreviations: HAN, hippuric acid nanocomposite; Dox, doxorubicin; HA, hippuric acid; Oxa, oxaliplatin.

and Caco 2 cell lines at incubation times $(24,48$, and 72 hours). However, doxorubicin and oxaliplatin drugs as well as combination of these drugs with HAN suppress the proliferation of MCF-7, MDA-MB231, and Caco2 tumor cells. The combination of these drugs with HAN are more efficient than the drugs alone against the growth of tumor cells. This result indicates that drug delivery to the tumor cell is noticeably enhanced by nanocomposites containing ZLH; however, in the nanocomposites system, drugs can reach the tumor cell membrane without early decomposition, since the drugs are stabilized and protected in the interlayer space of the ZLH layers. These results clearly confirm that the intercalation reaction not only prevents drug denaturation, but it also enhances the
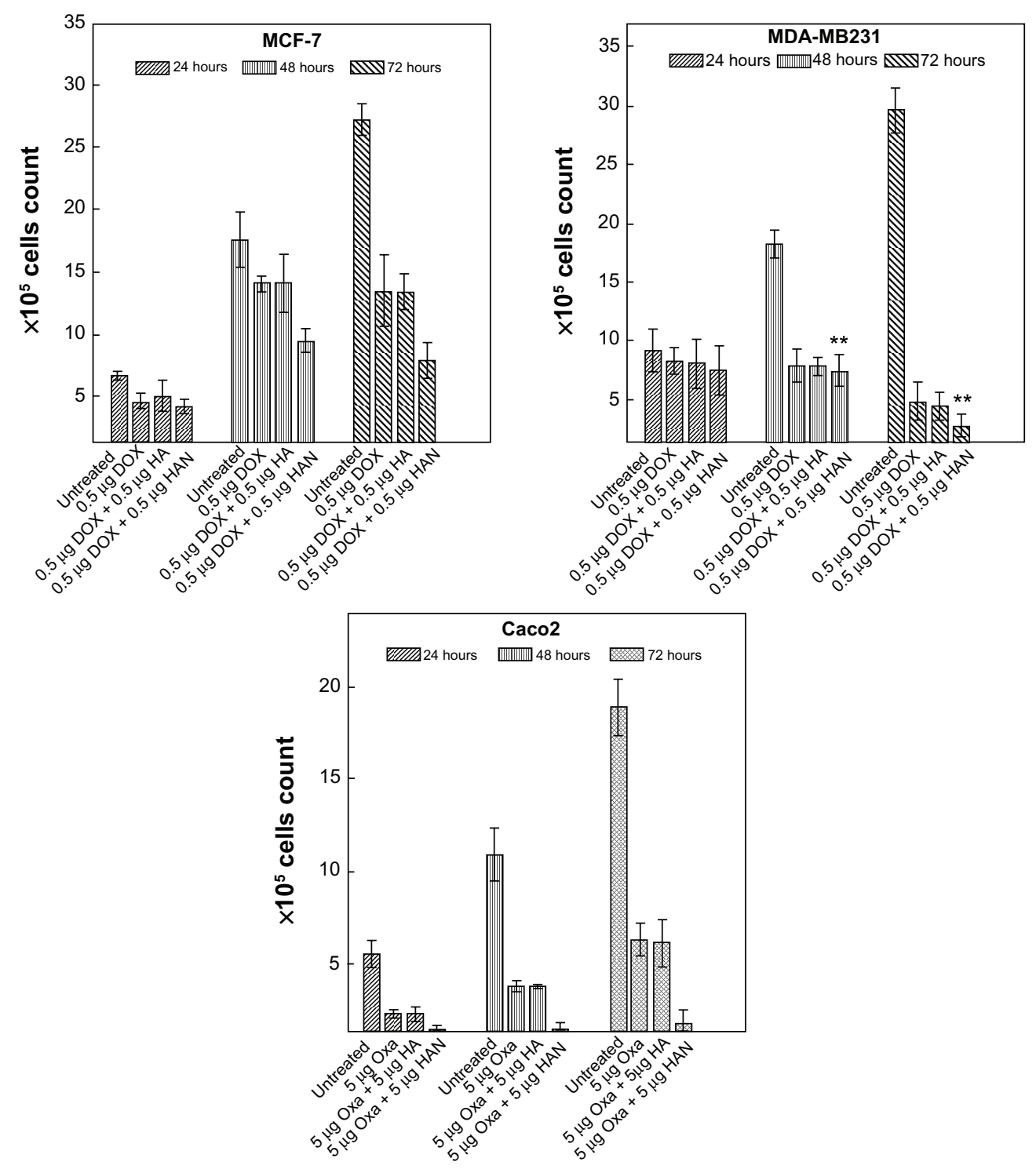

Figure 3 Antiproliferative assays of (A) MCF-7, (B) MDA-MB23I, and (C) Caco2 cell lines after, 24, 48, and 72 hours of treatment with free doxorubicin or oxaliplatin, and with a combination of doxorubicin or oxaliplatin with hippuric acid and HAN.

Abbreviations: Dox, doxorubicin; HA, hippuric acid; HAN, hippuric acid nanocomposite; Oxa, oxaliplatin. 
permeability of the drug into the target cell without any noticeable side effects. ${ }^{19}$

Supporting to MTT assay, trypan blue exclusion results confirmed that the combination of drugs with HAN can inhibit the cell proliferation in a time- and dose-dependent manner. In Table 2 and after 72 hours exposure, the co-treatment by oxaliplatin with HAN or doxorubicin with HAN results in greater antiproliferative effect of drugs.

At 48 and 72 hours, there appeared to be maximal and significant $(P<0.05)$ effects on cell proliferation, when compared to effects noted at 24 hours. This may be due to induce cell death and increasing of the exposure time. From the results of the trypan blue exclusion assay, increasing exposure time to combination of doxorubicin with HAN appeared to have a reduction effect on cell proliferation in MDA-MB231 more than can be seen in MCF-7 line under most circumstances. For MCF-7 cells, antiproliferation decreased at 48 hours (when compared to 24 hours) for both free doxorubicin and for the combination of doxorubicin hippuric acid, and then increases at 72 hours, but this effect was not seen for any other cells/drug treatment. This may be attributable to the high resistance of the estrogen receptor-positive breast cancer MCF-7 cell line to chemotherapy.

\section{Conclusion}

The intercalation of hippuric acid into a zinc-layered hydroxide, using a direct method to obtain the HAN nanocomposite, was successfully accomplished. The X-ray diffraction results confirmed the intercalation process in which hippuric acid lies between the interlayers. The MTT assay showed that the combination of HAN with doxorubicin or with oxaliplatin induced suppression of cell proliferation for the MCF-7, MDA-MB231, and Caco2 cell lines, as compared to free hippuric acid and free doxorubicin and oxaliplatin, which did not exhibit the same effects. This result can be proved by the antiproliferative study. Finally, the resulting combination of HAN with doxorubicin and oxaliplatin induced cytotoxicity in the MDA-MB231, MCF-7, and Caco2 cell lines.

\section{Acknowledgments}

We thank the Ministry of Higher Education of Malaysia for financial support under grant number FRGS/1/11/SG/ UPM/01/2 (Vot 5524165) for funding this research.

\section{Disclosure}

The authors report no conflicts of interest in this work. 


\section{References}

1. Carlino S. The intercalation of carboxylic acids into layered double hydroxides: a critical evaluation and review of the different methods. Solid State Ionics. 1997;98(1-2):73-84.

2. Williams GR, O'Hare D. Towards understanding, control and application of layered double hydroxide chemistry. J Mater Chem. 2006; 16(30):3065-3074.

3. Rives V. Layered Double Hydroxides: Present and Future. Hauppage, NY: Nova Science Publishers Inc; 2001

4. Minagawa K, Berber MR, Hafez IH, Mori T, Tanaka M. Target delivery and controlled release of the chemopreventive drug sulindac by using an advanced layered double hydroxide nanomatrix formulation system. J Mater Sci Mater Med. 2012;23(4):973-981.

5. Cavalieri SJ, Biehle JR, Sanders WE Jr. Synergistic activities of clarithromycin and antituberculous drugs against multidrug-resistant Mycobacterium tuberculosis. Antimicrob Agents Chemother. 1995; 39(7):1542-1545.

6. Stoppoloni D, Canino C, Cardillo I, et al. Synergistic effect of gefitinib and rofecoxib in mesothelioma cells. Mol Cancer. 2010;9:27.

7. Hamilton-Miller JM, Brumfitt W. Methenamine and its salts as urinary tract antiseptics: variables affecting the antibacterial activity of formaldehyde, mandelic acid, and hippuric acid in vitro. Invest Urol. 1977;14(4):287-291.

8. Kulcsár G. Synergistic potentiating effect of $\mathrm{D}(+)$-mannose, orotic, and hippuric acid sodium salt on selective toxicity of a mixture of 13 substances of the circulatory system in culture for various tumor cell lines. Cancer Detect Prev. 2000;24(5):485-495.

9. Hussein Al Ali SH, Al-Qubaisi M, Hussein MZ, Zainal Z, Hakim MN. Preparation of hippurate-zinc layered hydroxide nanohybrid and its synergistic effect with tamoxifen on HepG2 cell lines. Int J Nanomedicine. 2011;6:3099-3111.

10. Virag P, Perde-Schrepler M, Fischer-Fodor E, et al. Superior cytotoxicity and DNA cross-link induction by oxaliplatin versus cisplatin at lower cellular uptake in colorectal cancer cell lines. Anticancer Drugs. Epub May 18, 2012:1032-1038.
11. Zhou Y, Gu X, Ashayeri E, Zhang R, Sridhar R. Nicotine decreases the cytotoxicity of doxorubicin towards MCF-7 and KB-3.1 human cancer cells in culture. J Natl Med Assoc. 2007;99(4):319-327.

12. Smith L, Watson MB, O'Kane SL, Drew PJ, Lind MJ, Cawkwell L. The analysis of doxorubicin resistance in human breast cancer cells using antibody microarrays. Mol Cancer Ther. 2006;5(8):2115-2120.

13. Hussein MZ, Al Ali SH, Zainal Z, Hakim MN. Development of antiproliferative nanohybrid compound with controlled release property using ellagic acid as the active agent. Int J Nanomedicine. 2011;6:1373-1383.

14. Hussein Al Ali SH, Al-Qubaisi M, et al. Controlled-release formulation of antihistamine based on cetirizine zinc-layered hydroxide nanocomposites and its effect on histamine release from basophilic leukemia (RBL-2H3) cells. Int J Nanomedicine. 2012;7: 3351-3363.

15. Xingfu Z, Zhaolin H, Yiqun F, Su C, Weiping D, Nanping X. Microspheric organization of multilayered $\mathrm{ZnO}$ nanosheets with hierarchically porous structures. The Journal of Physical Chemistry C. 2008;112(31):11722-11728.

16. Doyle LA, Yang W, Abruzzo LV, et al. A multidrug resistance transporter from human MCF-7 breast cancer cells. Proc Natl Acad Sci US A. 1998;95(26):15665-15670.

17. Hiraga T, Williams PJ, Mundy GR, Yoneda T. The bisphosphonate ibandronate promotes apoptosis in MDA-MB-231 human breast cancer cells in bone metastases. Cancer Res. 2001;61(11):4418-4424.

18. Darmoul D, Lacasa M, Baricault L, et al. Dipeptidyl peptidase IV (CD 26) gene expression in enterocyte-like colon cancer cell lines HT-29 and Caco-2. Cloning of the complete human coding sequence and changes of dipeptidyl peptidase IV mRNA levels during cell differentiation. J Biol Chem. 1992;267(7):4824-4833.

19. Choy JH, Jung JS, Oh JM, et al. Layered double hydroxide as an efficient drug reservoir for folate derivatives. Biomaterials. 2004;25(15): 3059-3064.

\section{Publish your work in this journal}

Drug Design, Development and Therapy is an international, peerreviewed open-access journal that spans the spectrum of drug design and development through to clinical applications. Clinical outcomes, patient safety, and programs for the development and effective, safe, and sustained use of medicines are a feature of the journal, which

\section{Dovepress}

has also been accepted for indexing on PubMed Central. The manuscript management system is completely online and includes a very quick and fair peer-review system, which is all easy to use. Visit http://www.dovepress.com/testimonials.php to read real quotes from published authors. 